Www.jmscr.igmpublication.org

Index Copernicus Value: 79.54

ISSN (e)-2347-176x ISSN (p) 2455-0450

crossref DOI: https://dx.doi.org/10.18535/jmscr/v7i4.133

Journal Of Medical Science And Clinical Research

IGM Publication

An official Publication of IGM Publication

\title{
Role of Computed Tomography in Evaluation of Renal Masses
}

\author{
Authors \\ Dr Shrishail Adke ${ }^{1 *}$, Dr Dinesh Potdar ${ }^{2}$, Dr Pramod Shaha ${ }^{3}$, Dr Prakash Patil ${ }^{4}$, \\ Dr Amol Bhoite ${ }^{5}$, Dr Snehil Kumar ${ }^{6}$, Dr Bhupendra Pansare ${ }^{7}$ \\ ${ }^{1,6}$ Junior Resident, Department of Radiodiagnosis, Krishna Institute of Medical Sciences, Karad, \\ Maharashtra \\ ${ }^{2}$ Associate Professor, Department of Radiodiagnosis, Krishna Institute of Medical Sciences, Karad, \\ Maharashtra \\ ${ }^{3}$ Professor \& Head of Department of Radiodiagnosis, Krishna Institute of Medical Sciences, Karad, \\ Maharashtra \\ ${ }^{4}$ Assistant Professor, Department of Radiodiagnosis, Krishna Institute of Medical Sciences, Karad, \\ Maharashtra \\ ${ }^{5,7}$ Senior Resident, Department of Radiodiagnosis, Krishna Institute of Medical Sciences, Karad, \\ Maharashtra \\ *Corresponding Author \\ Dr Shrishail Adke
}

Department of Radiodiagnosis, Krishna Institute of Medical Sciences, Karad, Maharashtra, India

Email:shri.adke@gmail.com

\begin{abstract}
Background: Due to rapid pace in development of imaging techniques and increasing number of investigations being done, more number of renal masses are discovered incidentally during evaluation of unrelated or unspecific symptoms. Hence it is vital to differentiate neoplastic and non-neoplastic masses. Among the neoplastic masses, there is a need to differentiate benign and malignant masses so that appropriate treatment strategies like nephron sparing surgery, radio frequency ablation etc. can be planned at an early stage and avoiding unnecessary radical treatments for improved patients survival.

Methods: Thirty one non-consecutive patients belonging to all ages and both sexes admitted into the various clinical departments of Krishna institute of medical sciences, Karad who had presented with suspected renal mass by clinical signs and symptoms were examined on USG/CECT with protocol were included in our study.

Results: Ultrasound is the primary imaging modality of choice since it is inexpensive, easy to perform and no ionizing. On USG, the renal lesions are classified as solid or cystic. CECT for characterization and staging however histopathology remains gold standard.

Conclusions: Computed Tomography (Multidetector) is the imaging modality of choice for further evaluation and characterization. Contrast enhanced $C T$ is done in four phases viz., unenhanced, corticomedullary, nephrographic and excretory phase especially in cases of malignancy like renal cell carcinoma and benign conditions like angiomyolipoma and abscess is sufficient. However histopathological is the gold standard for diagnosis of various renal masses.
\end{abstract}

Keywords: Computed tomography, Renal masses. 


\section{Introduction}

The bilateral kidneys are retroperitoneal organs. Frequently several renal pathologies are encountered in routine clinical practice. Hence it is vital to differentiate neoplastic and nonneoplastic masses. Among the neoplastic masses, there is a need to further characterize them so that appropriate treatment strategies like nephronsparing surgery, radio frequency ablation etc. can be planned at an early stage and also unnecessary radical treatments can be avoided ${ }^{1}$. Earlier all solid renal masses showing enhancement were treated as instances of renal cell carcinoma (RCC), although proof generally was obtained only after radical nephrectomy.

The wide range of radiological investigations in the evaluation of renal lesions varies from plain abdominal radiograph, excretory urography, ultrasonography, radionuclide imaging, angiography, CT and MRI. Computerized tomography (CT) has a major role in evaluation and characterization of renal masses. ${ }^{2}$ In general, multi detector CT serves as a single step investigation for suspected renal masses. ${ }^{3}$

NEOPLASTIC

\begin{tabular}{|c|c|}
\hline BENIGN & MALIGNANT \\
\hline - Oncocytoma & - Renal cell carcinoma \\
- Angiomyolipoma & - Transitional cell carcinoma \\
- Cystic nephroma & - Squamous cell carcinoma \\
& - Wilms tumor \\
& - Renal sarcoma \\
& - Lymphoma \\
& - Metastasis \\
\hline
\end{tabular}

NON-NEOPLASTIC

\begin{tabular}{|l|l|}
\hline - Cyst & - Malakoplakia \\
- Abscess and pyonephrosis & - Hydatid disease \\
- Hematoma & - Vascular malformation \\
- Pseudotumour & - Xanthogranulomatous \\
& - Pyelonephritis \\
\hline
\end{tabular}

\section{Inclusion Criteria}

- Patients of both sex of any age group who had presented with suspected renal mass by: Clinical signs and symptoms suggestive of renal mass (Flank pain between ribs, hematuria) confirmed on USG examination.

\section{Exclusion Criteria}

- Patients who had history of allergy to intravenous contrast agents.

- Patients with deranged kidney function test.

- Patients with renal trauma.

\section{Material and Methods}

The study was conducted in the Department of Radio-diagnosis at Krishna Hospital after obtaining ethical committee clearance. Thirty one non-consecutive patients belonging to all ages and both sexes admitted into the various clinical departments who had presented with suspected renal mass by clinical signs and symptoms (palpable renal angle mass, renal angle pain, hematuria) were examined on USG/CECT with protocol were included in our study.

\section{Equipment's Used}

Ultrasonography: Siemens (Accuson x 300). 3.5 $\mathrm{MHz}$ frequency transducer.

CT machine: Siemens Emotion system 16 slice MDCT.

CT protocol for evaluation of the kidneys consists of both non enhanced and contrast-enhanced. 1. Unenhanced CT scan 2.Corticomedullary phase25-70s 3. Nephrographic phase-80-180s 4. Excretory phase- after 180s.

\section{Results}

In the present study, we observed cases with suspected renal mass. Various cases belonged to different age group and gender. Hence, in order to study their age distribution and gender wise distribution. We assessed their demographic characteristics. 
Table 1: Age Distribution of study subjects in the Study

\begin{tabular}{|l|c|c|}
\hline Age Group & No: of Patients & Percentage \\
\hline $\mathbf{1 - 1 0}$ & 1 & $3.22 \%$ \\
\hline $\mathbf{1 1 - 2 0}$ & 0 & 0 \\
\hline $\mathbf{2 1 - 3 0}$ & 2 & $6.45 \%$ \\
\hline $\mathbf{3 1 - 4 0}$ & 4 & $12.90 \%$ \\
\hline $\mathbf{4 1 - 5 0}$ & 10 & $32.25 \%$ \\
\hline $\mathbf{5 1 - 6 0}$ & 9 & $29.03 \%$ \\
\hline $\mathbf{6 1 - 7 0}$ & 4 & $12.90 \%$ \\
\hline$>\mathbf{7 0}$ years & 1 & $3.22 \%$ \\
\hline Grand Total & 31 & $100 \%$ \\
\hline
\end{tabular}

Table 2: Clinical Presentation of Renal Mass

\begin{tabular}{|l|c|c|}
\hline Clinical Complaints & No: of Patients & Percent \\
\hline Incidental Finding & 5 & $16.12 \%$ \\
\hline Abdominal mass & 7 & $22.58 \%$ \\
\hline Pain in abdomen & 7 & $22.58 \%$ \\
\hline Hematuria & 16 & $51.61 \%$ \\
\hline Fever & 5 & $16.12 \%$ \\
\hline Weight loss & 3 & $9.67 \%$ \\
\hline
\end{tabular}

Table 3: Distribution of Cases of Renal Mass in Our Study

\begin{tabular}{|l|c|c|}
\hline Diagnosis on CT & $\begin{array}{c}\text { Number of } \\
\text { cases }\end{array}$ & Percentage \\
\hline Renal cell carcinoma & 26 & $83.87 \%$ \\
\hline $\begin{array}{l}\text { Renal } \\
\text { Angiomyolipoma }\end{array}$ & 1 & $3.22 \%$ \\
\hline $\begin{array}{l}\text { Transitional cell } \\
\text { carcinoma }\end{array}$ & 1 & $3.22 \%$ \\
\hline Wilms tumor & 1 & $3.22 \%$ \\
\hline Bosniak IIF cyst & 1 & $3.22 \%$ \\
\hline Metastasis & 1 & $3.22 \%$ \\
\hline
\end{tabular}

Table 4: Clinical Presentation in Renal Cell Carcinoma

\begin{tabular}{|l|c|c|}
\hline Clinical Complaint & No: of Patients & Percentage \\
\hline Hematuria & 13 & $50 \%$ \\
\hline Abdominal mass & 6 & $23.07 \%$ \\
\hline Pain in abdomen & 4 & $15.38 \%$ \\
\hline Incidental & 4 & $15.38 \%$ \\
\hline
\end{tabular}

Table 5: USG Features of RCC lesions

\begin{tabular}{|l|c|c|c|}
\hline \multicolumn{2}{|l|}{ USG Appearance } & $\begin{array}{c}\text { No: of } \\
\text { Patients }\end{array}$ & Percentage \\
\hline Hypoechoic & Solid & 7 & $26.92 \%$ \\
\hline Heterogenous & Solid & 15 & $57.69 \%$ \\
\cline { 2 - 4 } & $\begin{array}{c}\text { Solid with } \\
\text { cystic }\end{array}$ & 4 & $15.38 \%$ \\
\hline
\end{tabular}

Table 6: Distribution of Characteristics in Renal Cell Carcinoma

\begin{tabular}{|l|c|c|}
\hline RCC Characteristics & $\begin{array}{c}\text { Number of } \\
\text { cases }\end{array}$ & Percentage \\
\hline Calcification & 5 & $19.23 \%$ \\
\hline Fat attenuation & 0 & 0 \\
\hline $\begin{array}{l}\text { Heterogeneous } \\
\text { enhancement }\end{array}$ & 24 & $92.30 \%$ \\
\hline $\begin{array}{l}\text { Homogenous } \\
\text { enhancement }\end{array}$ & 2 & $7.69 \%$ \\
\hline
\end{tabular}

Table 7: Local Extent Evaluation in CT

\begin{tabular}{|l|c|c|}
\hline Extent & No: of Lesions & Percentage \\
\hline Perinephric extension & 5 & $19.23 \%$ \\
\hline $\begin{array}{l}\text { Beyond perirenal } \\
\text { fascia }\end{array}$ & 6 & $23.07 \%$ \\
\hline $\begin{array}{l}\text { Ipsilateral adrenal } \\
\text { involvement }\end{array}$ & 2 & $7.69 \%$ \\
\hline $\begin{array}{l}\text { Pelvicalyceal } \\
\text { involvement }\end{array}$ & 4 & $15.38 \%$ \\
\hline Renal vein thrombus & 3 & $11.53 \%$ \\
\hline IVC thrombus Lymph & 3 & $11.53 \%$ \\
\hline $\begin{array}{l}\text { Regional } \\
\text { adenopathy }\end{array}$ & 3 & $11.53 \%$ \\
\hline
\end{tabular}

Figure 1: T Staging

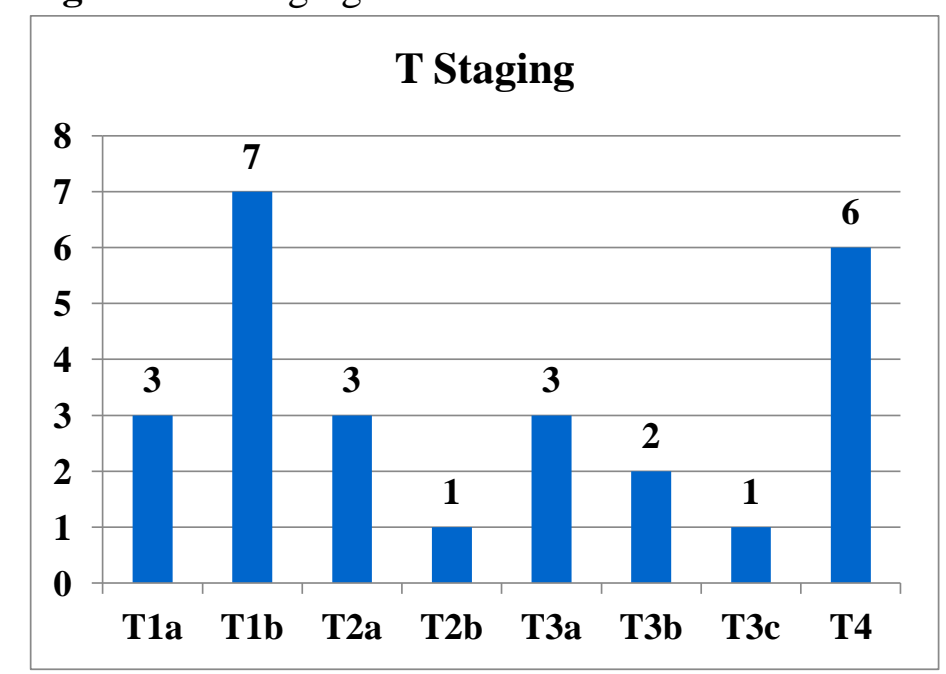

Table 8: Staging of Renal Cell Carcinoma in Our Study

\begin{tabular}{|l|c|c|}
\hline Stage & $\begin{array}{c}\text { No: of } \\
\text { Patients }\end{array}$ & Percentage \\
\hline 1 & 10 & $38.46 \%$ \\
\hline 2 & 4 & $15.38 \%$ \\
\hline 3 & 6 & $23.07 \%$ \\
\hline 4 & 6 & $23.07 \%$ \\
\hline Total & 26 & $100 \%$ \\
\hline
\end{tabular}


Table 9: Histopathological Correlation

\begin{tabular}{|l|c|c|}
\hline $\begin{array}{l}\text { HPR Testing of } \\
\text { RCC }\end{array}$ & Number of cases & Percentage \\
\hline Positive & 25 & $96.15 \%$ \\
\hline Negative & 1 & $3.84 \%$ \\
\hline Total & 26 & $100 \%$ \\
\hline
\end{tabular}

Table 10: Comparison of CT as a modality for diagnosis of renal mass (with respect to HPR)

\begin{tabular}{|c|c|c|c|c|}
\hline & \multicolumn{2}{|c|}{$\begin{array}{l}\text { HPR diagnosed } \\
\text { RCC }\end{array}$} & \multirow{2}{*}{ Tota } \\
\hline & & Positive & Negative & \\
\hline \multirow{2}{*}{$\begin{array}{l}\text { CT } \\
\text { Diagnosis } \\
\text { of RCC }\end{array}$} & Positive & 25 & 1 & 26 \\
\hline & Negative & 1 & 4 & 5 \\
\hline \multicolumn{2}{|l|}{ Total } & 26 & 5 & 31 \\
\hline
\end{tabular}

\section{Sensitivity and Specificity of CT as a diagnostic modality of RCC}

From the present study, we found one case of false positive which turned out to mesenchymal tumor PNET and one case of false negative detected by CT scan which was actually a case of cystic RCC while evaluating renal masses. Based on recorded findings, we calculated sensitivity and specificity of CT scan as a reliable diagnostic modality for diagnosis of renal cell carcinoma. From this study, we observed Sensitivity of $96.15 \%$ and Specificity of $80 \%$.

We calculated the diagnostic accuracy of CT in diagnosis of malignant renal mass lesion which came out to be $96.77 \%$.

Table 11: Sensitivity and specificity of CT scan to diagnose renal mass.

\begin{tabular}{|l|l|}
\hline Parameters & Values \\
\hline Sensitivity & $96.15 \%$ \\
\hline Specificity & $80 \%$ \\
\hline
\end{tabular}

\section{Illustration No.1}
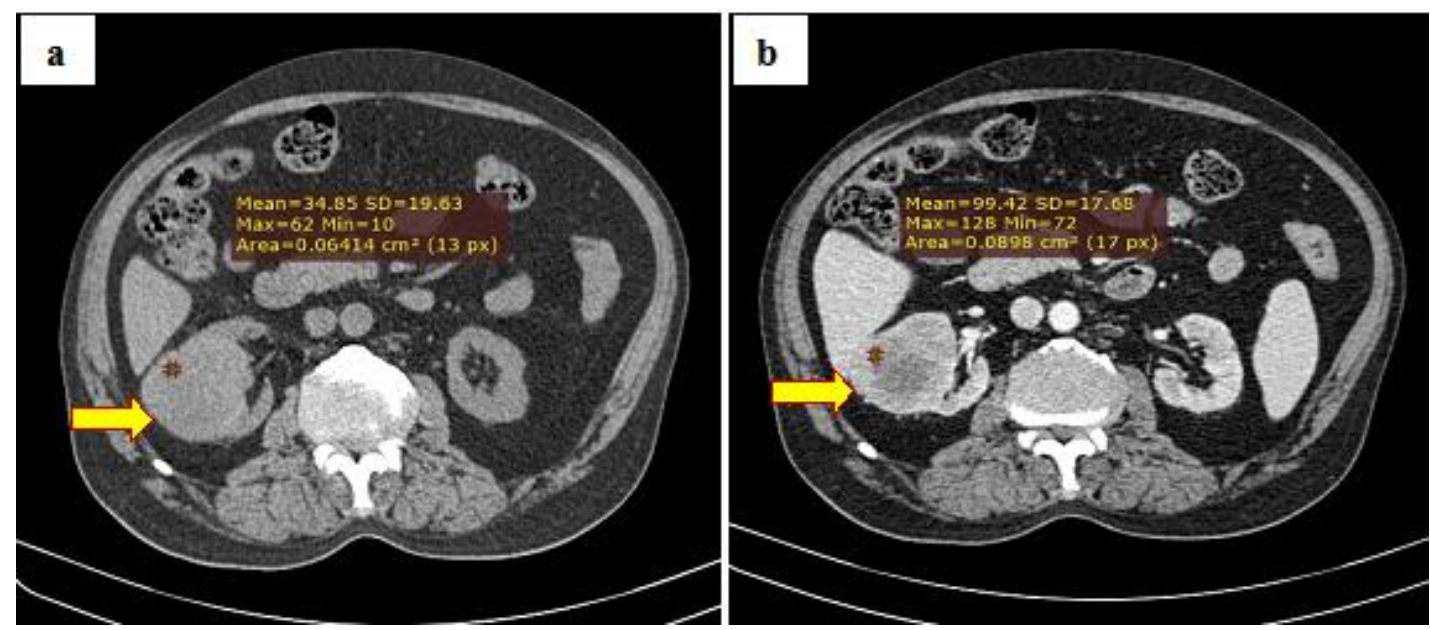

Renal Transitional Cell Carcinoma: One case of renal transitional cell carcinoma was diagnosed which contributed to $3.22 \%$ which was seen as infiltrative heterogeneously enhancing mass with maintained renal contour along renal pelvis with upper ureteral thickening and metastasis to liver metastasis.

Bosniak Cyst: One case of Bosniak IIF cyst was seen in 55 year male presenting which was incidental detected on routine scan. On USG, there was a large cystic lesion with thick septations \& nodular wall thickening noted in lower pole of right kidney. On CECT there was enhancement of the septations with subtle enhancement of nodular wall. There was no invasion of renal vein or IVC. Features were suggestive of Bosniak IIF cyst and diagnosis of Cystic renal cell carcinoma was made on HPR.

Angiomyolipoma: One case of sporadic angiomyolipoma was seen in middle aged male located in upper pole of left kidney. The lesions were heterogeneously hyperechoic on USG and showed heterogeneous post contrast enhancement with fat attenuation on CT.

Renal Metastasis: One case of renal metastases was seen in 65 year male who was known case of lung carcinoma on treatment for same. Lesion was hypoechoic on ultrasound and on CT lesion was showing peripheral enhancement with central necrotic non enhancing areas. 


\section{JMSCR Vol||07||Issue||04||Page 791-800||April}

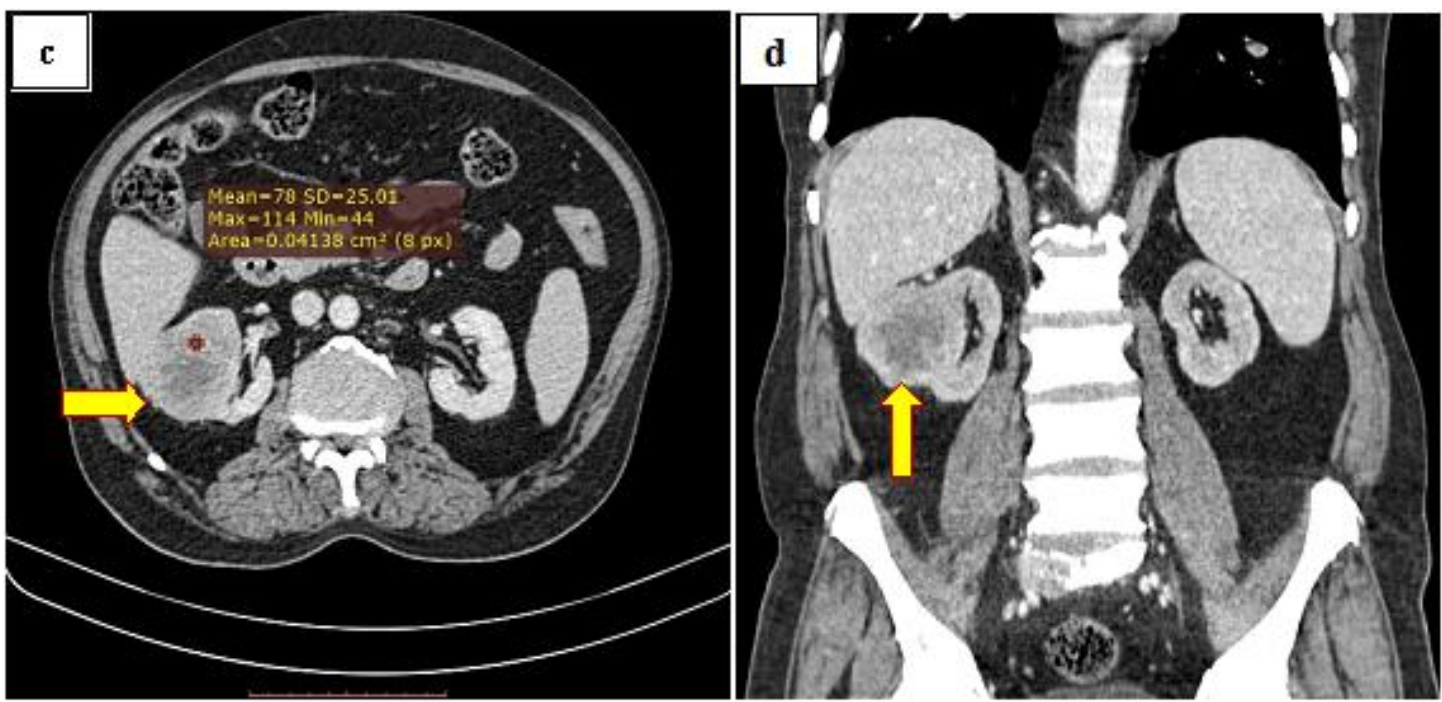

Case of renal cell carcinoma of ball type lesion in middle aged male patient a) Axial unenhanced CT showing iso to hyperdense mass. (b) and (c) CMP \& NP showing heterogenous enhancement. (d) Coronal MPR image is helpful in evaluation of contour, location \& extent.

\section{Illustration No.2}
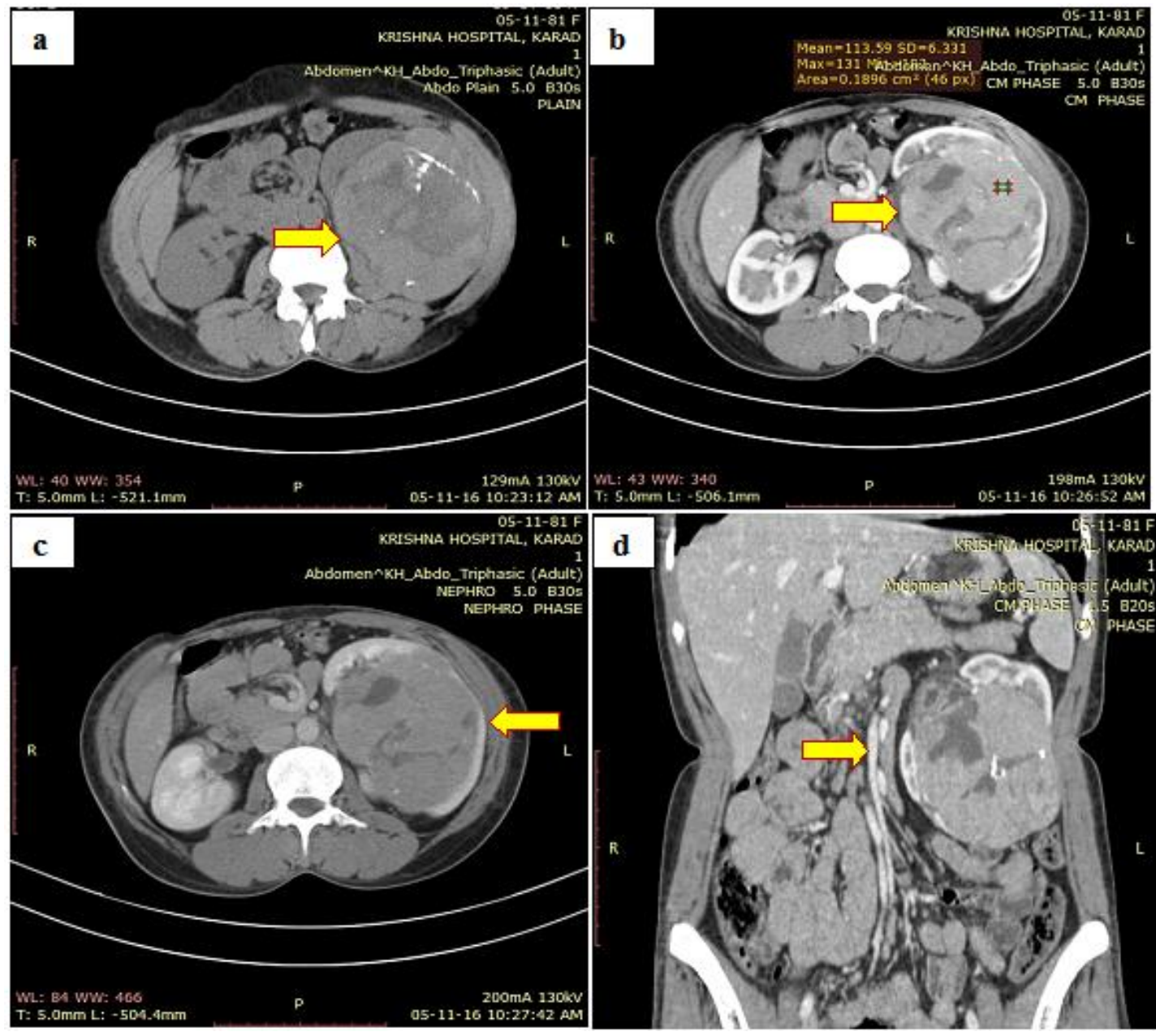

Case of renal cell carcinoma in middle aged male who presented with hematuria on CT a large lesion involving whole of the left kidney with maintained contour with abnormal renal axis and displacing adjacent structure. (a) Unenhanced CT shows heterogenous lesion with peripheral calcification. (b) and (c) CMP \& NP showing heterogenous enhancement. (d) Coronal MPR image demonstrating entire involvement of left kidney. 


\section{Illustration No.3}
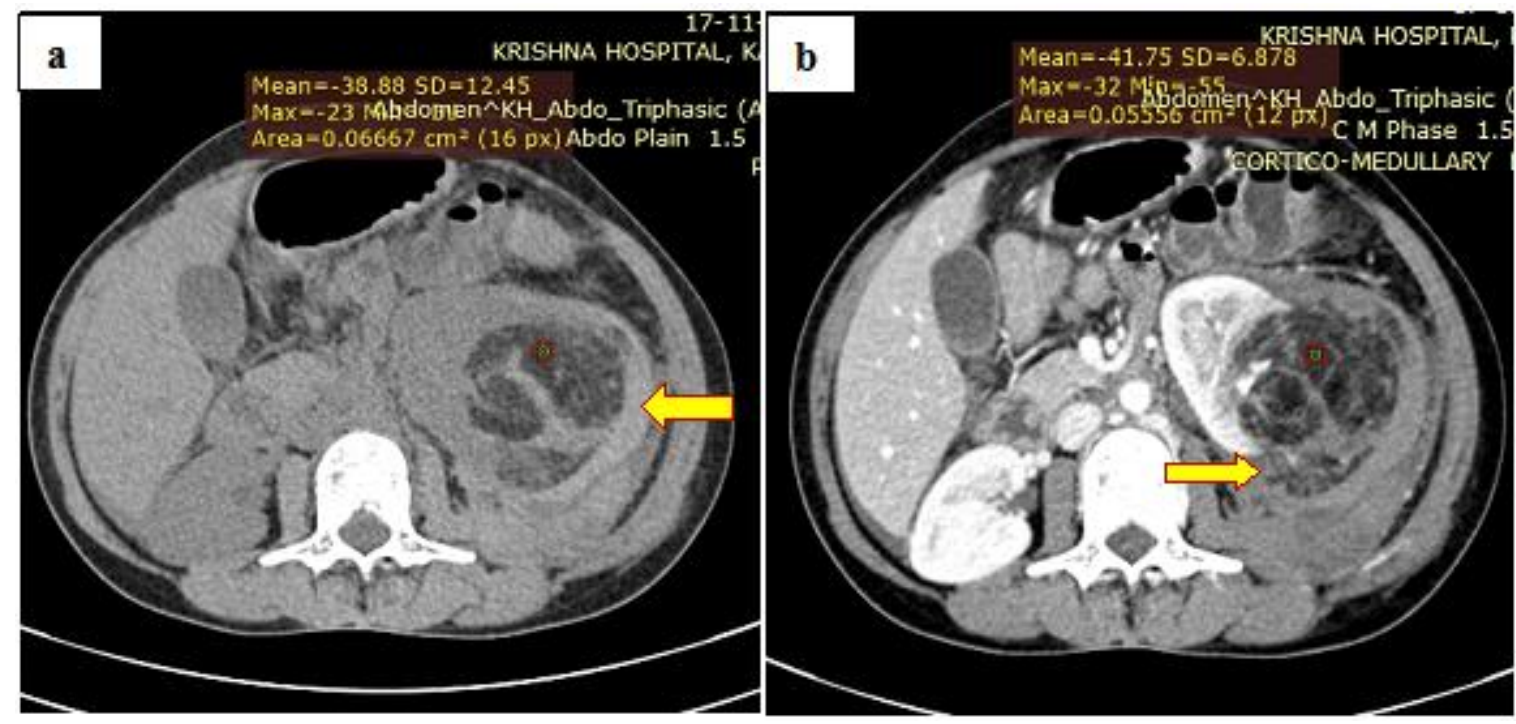

Case of Angiomyolipoma in 48 year old male patient (a) Axial Unenhanced CT demonstrates a well defined lesion arising from left kidney with fat attenuation and surrounding hyperdense collection. (b) Axial contrast image demonstrates heterogenous enhancement with non enhancing hyperdense collection.

\section{Discussion}

Demographic characteristic: We observed that majority of the cases presented with suspected renal mass based on clinical findings, belonged to age group of 41-50 years $(n=10,32.25 \%)$, followed by 51-60 years which represents 9 cases (29.03\%), age groups 31-40 years and 61-70 years represents similar proportion of cases, i.e. 4 $(12.90 \%)$. In the present study we observed only one pediatric case of age 5 years $(3.22 \%)$ and one case above 70 years of age $(3.22 \%)$.

We studied the gender-wise distribution of the study cases and observed that majority of the cases presented with suspected renal mass were males $(\mathrm{n}=19,61.29 \%)$, followed by females $(\mathrm{n}=12, \quad 38.70 \%)$. It shows clear male predominance of cases with renal mass.

Clinical Presentation: We assessed clinical presentation of the study subjects, in order to correlate the findings clinically with further diagnostic methods. We found that hematuria was the commonest clinical presentation of the cases $(\mathrm{n}=16,51.61 \%)$, followed by pain in abdomen $(\mathrm{n}=7,22.58 \%)$ and abdominal mass $(\mathrm{n}=7$, $22.58 \%)$.
Presence of fever, and weight loss were the least common findings in our study. While 5 cases $(16.12 \%)$ reported it to be an incidental finding.

Spectrum of Diagnosis in Study: All the cases with suspected renal mass were subjected to a computed tomography examinations. We reported that majority of the cases of renal mass found to be a renal cell carcinoma $(n=26,83.87 \%)$. Other cases were Renal Angiomyolipoma, Transitional cell carcinoma, Wilms tumor, Bosniak IIF cyst and Metastasis (One case each)

Since the imaging finding and implications of various types of renal masses were different, the individual diseases will be discussed separately under different headings.

Renal Cell Carcinoma: Renal cell carcinoma was the most common renal mass observed in our study accounting for 26 patients out of 31 cases presented with renal mass.

Age and Sex: We analyzed age distribution of cases among the cases of renal cell carcinoma. It was observed that majority of the cases of RCC belonged to age group of 41-50 years $(n=9$, $34.61 \%)$, followed by 51-60 years $(n=7,26.92 \%)$, $31-40$ years $(n=4,15.38 \%)$ and so on.

We analyzed gender-wise distribution of cases among the cases of renal cell carcinoma. It was 
found that male gender was still predominant $(\mathrm{n}=15,57.69 \%)$, but the difference was not statistically significant.

Shalini Agnihotri et $\mathrm{al}^{4}$ in 2014 has shown that the mean age at diagnosis was $55.15 \pm 13.34$ (median 56, range 14-91) years. Male preponderance was seen in patients of all age groups. Which were comparable with our study.

In a study from Surveillance Epidemiology and End Results (SEER) database, majority of RCC cases at presentation were between $60-69$ or 70-79 years of age and only 42 per cent of patients presented in $<60$ years of age 5 . In our present study, RCC accounted for $61.9 \%$ in less than 60 years of age which was comparable with other Indian studies thus showing the relatively younger age group of occurrences of renal cell carcinoma in India.

Clinical complaints: We assessed the clinical presentation of renal cell carcinoma cases, in order to correlate them clinically. It was observed that the hematuria was still a commonest presentation in cases of renal cell carcinoma $(n=13,50 \%)$, followed by abdominal mass $(n=6,23 \%)$, and pain in abdomen $(n=4,15.38 \%)$. In 4 cases $(15.38 \%)$, diagnosis of RCC was an incidental finding.

Donald G.Skinner et $\mathrm{al}^{6}$ has shown that the classical triad of renal cell carcinoma was seen only in $9 \%$ with the hematuria being the most common complaint in $60 \%$ which was comparable with our studies.

Location: We assessed the location of renal cell carcinoma among the study subjects. It was observed that in majority of cases lesions were present on upper pole $(n=7,26.92 \%)$, followed by lower pole among 6 cases and inter pole, whole kidney among 4 cases each.

Imaging Appearance: Majority of the cases reported heterogeneous solid appearance $(n=15$, $57.69 \%$ ), followed by 7 cases with hypoechoic solid appearance and 4 cases with heterogeneous solid with cystic appearance.

In the present study, we assessed the computed tomography characteristics of renal cell carcinoma lesions. It was reported that majority of the cases showed heterogeneous enhancement $\quad(n=24$, $92.30 \%$ ), 5 cases reported calcifications and 2 cases reported homogenous enhancement.

Local extension: Local extension of renal cell carcinoma lesions in our study subjects. Majority of cases reported of having local extension beyond peri-renal fascia $(n=6,23.07 \%)$, followed by Perinephric extension among 5 cases $(19.23 \%)$, Pelvicalyceal involvement in 4 cases $(15.38 \%)$ each. Table 12 shows other rare local extension of renal cell carcinoma.

In the given study, we also assessed surrounding organs involved in cases of renal cell carcinoma. It was found that inferior vena cava was most commonly involved $9 n=3,11.53 \%$, followed by ipsilateral adrenal gland and liver in cases of RCC ( 2 cases each). Other rare organs/viscera involved are colon, psoas/paravertebral muscle and pancreas.

P Hatimota et $\mathrm{al}^{7}$ has shown that Renal and IVC invasion was seen in $13.1 \%$ of patients which is comparable with our study

Staging: In the present study, we categorized various cases of RCC according to their TNM staging. In $\mathrm{T}$ staging, majority of the cases belonged to the stage $\mathrm{T} 1 \mathrm{~b} \quad(\mathrm{n}=7,26.92 \%)$, followed by T1a, T2a, T3a (3 cases in each), followed by T3b ( 2 cases). In $\mathrm{N}$ staging, only 3 cases showed lymph nodal involvement, and 5 cases of metastasis ( $\mathrm{M}$ staging). There was direct correlation between patient's clinical complaint and the stage of disease. In the present study, majority of the cases of renal cell carcinoma belonged to stage $1(n=10,38.46 \%)$, followed by stage 3 and 4 ( 6 cases in each), followed by stage 4 with 2 cases $(15.38 \%)$.

Ke hung tusi et $\mathrm{al}^{8}$ in 2000 showed Stage I lesions were observed in $62.1 \%$ of patients with incidental renal cell carcinoma and in $23 \%$ with symptomatic renal cell carcinoma. In contrast, stage IV lesions were present in $27.4 \%$ of patients with incidental versus $54 \%$ with symptomatic renal cell carcinoma. Thus, incidental lesions were of significantly lower stage than those causing 
symptoms $(\mathrm{p}<0.001)$. These data correlate with our study.

Metastasis: Distant metastasis was found in 23\% at time of presentation in our study. We assessed the different sites for metastasis in cases of renal cell carcinoma in our study. Lungs and liver were the commonest organs involved for metastasis in cases of RCC (2 cases each). Pleura and bones were rare sites for metastasis in our study

Jemal A et $\mathrm{al}^{9}$ in 2006 showed, 25-30\% of patients with RCC have metastases at time of presentation which is comparable with our study. This indicates the need of effective methods for early diagnosis of renal cell carcinoma. Lung was the commonest site of metastasis accounting for $33.3 \%$ of metastasis followed by ${ }^{\circ}$ bones and liver $(22.2 \%)$.Multiple sites of metastasis was found in $33.3 \%$.

B Sivaramakrishna et $\mathrm{al}^{10}$ in 2005 has shown Ten of the 39 patients(25.6\%)developed multiple metastases with lung being the commonest site of metastases $(37 \%)$, followed by skeletal system (22\%), liver (19\%) which is similar to our study.

Wilms tumor: There was a single case of Wilms Tumor was seen in our study of 5 years age, accounting for commonest pediatric renal mass which is similar with other studies. Both had positive beak sign thus locating the organ of origin. There was no evidence of calcification or fat attenuation. On ${ }^{\circ}$ Post contrast, both the lesions showed heterogeneous contrast enhancement with solid and cystic areas. There were no evidence of renal vein or IVC invasion or distant metastasis in our study Comparison with previous study could not be done due to inadequate number of cases due to less number of pediatric referrals in our institute.

Renal Transitional Cell Carcinoma: There was one case of transitional cell carcinoma who presented with hematuria. On US there was a mixed echogenic mass in the dilated renal pelvis of right kidney. On CT the mass was in central location with density greater than that of urine showing minimal heterogeneous enhancement after contrast, centrifugal extension, and invasion of renal parenchyma but maintaining the shape of the kidney and extending into upper ureter.

Raza SA et al ${ }^{11}$ showed Six CT features were most diagnostically specific for identifying intrarenal ${ }^{\circ}$ TCCs: tumor centered within the collecting system; focal filling defect in the pelvicalyceal system; preserved renal shape; absence of cystic or necrotic change; homogeneous tumor enhancement; and tumor extension toward the ureter pelvic junction (sensitivity, 68-82\%; specificity, 79-89\%; AUC, 0.75-0.84).

Bosniak Cyst: One case of Bosniak IIF cyst was seen in old aged male with septa and wall thickening. On contrast septal enhancement was noted. Patient further underwent for biopsy due to indeterminate imaging findings \& to rule out malignancy, it was found out to be cystic RCC on histopathology.

Angiomyolipoma: One case of asymptomatic sporadic ${ }^{\circ}$ angiomyolipoma in middle aged male was seen with the lesion appearing hyperechoic on USG and showing fat attenuation in CT. In one of the case, it was multiple small lesions involving bilateral kidney in patient of known case of breast carcinoma who came for metastasis work up. Presence of fat attenuation in these lesions confidently allowed to make diagnosis of angiomyolipoma and thus ruling out metastasis.

Histopathological Correlation: In this study, in order to confirm the diagnosis of renal masses, the cases of renal masses underwent histopathological correlation which was carried after postoperative specimen or through biopsy. It was observed that 25 cases $(96.15 \%)$ cases out of total 26 cases that were diagnosed positive by computed tomography were diagnosed positive by HPR methods. Only one case was diagnosed FALSE POSITIVE by CT scan which turned out to be ${ }^{\circ}$ PNET on histopathology and one case which was actually a case of cystic RCC was diagnosed FALSE NEGATIVE by $\mathrm{CT}$ scan and given as Bosniak cyst II.

Sensitivity and Specificity of CT as a diagnostic modality of RCC: From the present study, we found one case of false positive and one case of 
false negative detected by CT scan while evaluating renal masses. Based on recorded findings, we calculated sensitivity and specificity of CT scan as a reliable diagnostic modality for diagnosis of renal cell carcinoma. From this study, we observed Sensitivity of ${ }^{\circ} 96.15 \%$ and Specificity of $80 \%$.

We calculated the diagnostic accuracy of CT in diagnosis of malignant renal mass lesion which came out to be $96.77 \%$.

\section{Conclusion}

Ultrasound is the initial imaging modality of choice in cases of renal masses since its inexpensive, easy to perform and there is no radiation exposure. Computed Tomography (Multidetector) is the imaging modality of choice for further evaluation and characterization. $\mathrm{CT}$ is done in four phases viz., unenhanced, corticomedullary, nephrographic and excretory phase especially in cases of suspected malignancy. Presence of macroscopic fat attenuation in the lesion confidently allows to make diagnosis of Angiomyolipoma. Presence of Ball or bean type of lesion based on whether it alters the renal contour or not, respectively, helps to narrow the differential diagnosis. Presence of any exophytic enhancing solid lesion especially when associated with heterogeneous enhancement with areas of necrosis and cystic changes in the kidney are regarded as renal cell carcinomas. MDCT is the imaging modality of choice for evaluating local extension and staging of renal lesion.

Further, MDCT provides preoperative renal vascular status viz, renal artery anatomy, accessory arteries, normal variants, renal vein/IVC invasion and for evaluating the hyper enhancing metastasis in corticomedullary phase. While commenting on the IVC, care should be taken not to mistake unopacified lower extremity blood for filling defect and should be correlated with other phases. Local extension of the disease is done in nephrographic phase. Pelvicalyceal status is determined in excretory phase. Such incidental renal masses when show heterogenous enhancement, necrosis, calcification is highly suggestive of renal cell carcinomas. However histopathology remains the gold standard for diagnosis of RCC.

\section{References}

1. Catalano C, Fraioli F, Laghi A, Napoli A, Pediconi F, Danti M, et al. High-resolution multidetector $\mathrm{CT}$ in the preoperative evaluation of patients with renal cell carcinoma. AJR Am J Roentgenol. 2003;180(5):1271-7.

2. Tsili AC, Argyropoulou MI. Advances of multidetector computed tomography in the characterization and staging of renal cell carcinoma. World J Radiol. 2015;7(6):11027.

3. Ng CS, Wood CG, Silverman PM, Tannir NM, Tamboli P, Sandler CM. Renal cell carcinoma: diagnosis, staging, and surveillance. AJR Am J Roentgenol. 2008;191(4):1220-32.

4. Agnihotri, S., Kumar, J., Jain, M., Kapoor, R. \&Mandhani, A. Renal cell carcinoma in India demonstrates early age of onset \& a late stage of presentation. Indian J. Med. Res. 140, 624-629 (2014).

5. Sun, M. et al. A stage-for-stage and gradefor-grade analysis of cancer-specific mortality rates in renal cell carcinoma according to age: a competing-risks regression analysis. Eur. Urol. 60, 11521159 (2011).

6. Skinner, D. G., Colvin, R. B., Vermillion, C. D., Pfister, R. C. \&Leadbetter, W. F. Diagnosis and management of renal cell carcinoma A clinical and pathologic study of 309 cases. Cancer 28, 1165-1177 (1971).

7. Hatimota, P., Vashist, S., Aggarwal, K., Kapoor, A. \& Gupta, N. P. Spectrum of US and CT findings in renal neoplasms with pathologic correlation. Indian J. Radiol. Imaging 15, 117 (2005). 
8. Tsui, K.-H. Et al. Renal Cell Carcinoma: Prognostic Significance of Incidentally Detected Tumors. J. UROL. 163, 426-430 (2000).

9. Jemal, A. et al. Cancer statistics, 2006. CA. Cancer J. Clin. 56, 106-130 (2006).

10. Sivaramakrishna, B. et al. Pattern of metastases in renal cell carcinoma: A single institution study. Indian J. Cancer 42, 173 (2005).

11. Raza SA, Sohaib SA, Sahdev A, Bharwani $\mathrm{N}$, Heenan S, Verma $\mathrm{H}$, et al. Centrally infiltrating renal masses on CT: differentiating intrarenal transitional cell carcinoma from centrally located renal cell carcinoma. AJR Am J Roentgenol. 2012;198(4):846-53. 